\title{
EL TURISMO 2.0. UN NUEVO MODELO DE PROMOCIÓN TURÍSTICA
}

\author{
Eva Sánchez Amboage ${ }^{1}$ \\ Universidad de A Coruña \\ eva amboaxe@hotmail.com
}

Material original autorizado para su primera publicación en la revista académica REDMARKA. Revista Digital de Marketing Aplicado.

https://doi.org/10.17979/redma.2011.01.06.4719

Material autorizado para su primera publicación en la revista académica como artículo.

\section{RESUMEN}

Como consecuencia del empleo masivo de Internet el perfil del cliente ha cambiando, llegando a convertirse en lo que los entendidos llaman "Adprosumer". Se unen en este término distintos conceptos: AD (anuncio), PRO (productor), SUMER (consumidor). Es esta una forma de resumir al nuevo cliente de la Web 2.0, el que recomienda, participa de la promoción y consume un producto. Ante este nuevo vocablo y nuestro interés por el sector turístico nos hacemos las siguientes cuestiones ¿Están las empresas turísticas adaptándose a este nuevo cliente? ¿Han cambiado su forma de promocionar los servicios turísticos? ¿Cómo influye el 2.0 en el sector turístico?

A lo largo del presente artículo intentaremos contestar a estas interrogaciones a través del análisis del Turismo 2.0.

Palabras clave: Turismo, Web 2.0, Promoción, Nuevas Tecnologías

\section{ABSTRACT}

TOURISM 2.0: A NEW MODEL OF TOURISM PROMOTION

As a result of massive use of Internet customer profile has changed, becoming experts in what they call "Adprosumer." Come together in this term in many

1 Diplomada en Turismo por la Universidad de A Coruña. Máster Oficial en Dirección y Planificación del Turismo por la Universidad de A Coruña. 
ways: AD (ad), PRO (producer), SUMER (consumer). Is this a way of summarizing the new Web 2.0 client, which recommends, part of the promotion and consume a product. Faced with this new term and our interest in the tourism sector following issues, Are tourism businesses adapt to this new client? Have they changed their way of promoting tourism services? 2.0 How does the tourism sector?

Throughout this article we answer these questions through an analysis of Travel 2.0.

Keywords: Tourism, Web 2.0, Promotion, New Technologies 


\section{INTRODUCCIÓN}

Según Carlos Vogeler ${ }^{2}$ los inicios del turismo se remontan a finales del Renacimiento donde jóvenes ingleses de familias pudientes viajaban durante un largo período (dependía del nivel económico familiar pero podía llegar a tres o cinco años) por todo el continente Europeo con propósitos de enriquecimiento cultural y experiencia personal. Este movimiento es conocido como "El Gran Tour".

Por aquel entonces la promoción de este turismo embrionario era distinta a la que conocemos hoy en día, aunque bien es cierto que ambas guardan similitudes. Su forma de expansión era, principalmente, el boca a oreja entre la clase media-alta inglesa que veían el Gran Tour como una actividad exclusiva para la formación de sus hijos, así como una distinción frente al resto de familias inglesas que no podían permitirse que sus descendientes disfrutaran de este viaje.

El turismo actual guarda multitud de diferencias evidentes con respecto al Gran Tour pero en cuanto a promoción se refiere aunque el concepto sigue siendo el mismo, difundir un mensaje y que éste tenga una respuesta del público objetivo al que va dirigido, los medios empleados son muy distintos. Los contrastes entre ambas promociones surgen debido a dos aspectos clave:

- $\quad$ Cambio en la percepción del turista

- Introducción de nuevas tecnologías

El turista y con él el turismo han cambiando a lo largo de los años, el cliente se vuelve más exigente, sabe y tiene información de lo que compra y como tal exige una calidad y un producto o servicio que se adapte a sus necesidades.

En este contexto cobran gran importancia las nuevas tecnologías, en especial y debido a su reciente interés, las Redes Sociales.

\footnotetext{
${ }^{2}$ Vogeler, C (2000). El mercado turístico. Estructura, operaciones y procesos de producción 
Ya no sirve que la empresa o administración nos intente convencer de "lo bueno que es su producto" necesitamos además, que otros clientes o usuarios nos den su propia opinión, nos aconsejen y nos convenzan de que un producto o un servicio es apto para la compra. Pero este fenómeno no sólo aparece en la interacción entre empresa-cliente, sino también entre la sociedad o las personas en general. En unos casos la curiosidad y en otros el estar bien informado mueven a la gente hacia la Web 2.0.

Internet y las Redes Sociales han revolucionado la forma de viajar, ambas herramientas son clave en todas fases del viaje:

"Pre-viaje": Ios futuros turistas buscan información a través de la red. Leen información en blogs y foros, revisan fotografías de viajes de sus amigos en las redes sociales, piden opiniones a otros viajeros etc.

Durante el viaje: Muchos turistas que utilizan las redes sociales de forma habitual tienen la necesidad de mantener informados a sus "amigos" sobre su viaje, subir las fotografías en el momento y que el resto de amigos o seguidores puedan hacer los comentarios pertinentes.

"Post-viaje": Una vez finalizado el viaje las redes sociales cobran más importancia, si cabe, aparece ahora la oportunidad de comentar la experiencia, informar a los compañeros de las vivencias ocurridas y sobre todo recomendar lugares, hoteles, restaurantes, etc. Opiniones que son muy seguidas por propietarios de establecimientos turísticos.

En este artículo nos centraremos en cómo las nuevas tecnologías modifican la forma tradicional de promocionar el turismo.

\section{PROMOCIÓN 2.0}

Cada vez más se incrementa el interés de muchas empresas y organizaciones por saber si publicitarse o anunciarse en la Web 2.0 es rentable para el negocio. Los empresarios son conscientes de que la Red se está posicionando como uno de los medios más utilizados por el público en general. Por ello, las 
empresas han destinando mayores cantidades de dinero a estas herramientas publicitarias y de promoción a través de Internet.

Los beneficios de ocupar un sitio dentro de la Red son hoy evidentes, pero entre ellos podemos destacar los siguientes:

- La interactividad y realimentación. Internet permite estar conectado con los clientes en todo momento, recibiendo así un trato más eficaz y personalizado.

- Información sobre el cliente. Los datos que nos ofrece el cliente en un momento dado (muchas empresas que se anuncian por Internet piden como requisito para recibir información, rellenar algunos datos como: nombre, teléfono, dirección de correo electrónico, gustos y preferencias, etc.) pueden ser almacenado en una base de datos y servir para promociones posteriores, enviar información a cerca de la empresa, y en definitiva tener localizable al cliente.

- Reducir costes. Gracias a la Red se pueden eliminar intermediarios e incluso personal. Esto favorece la reducción de costes y por lo tanto, la disminución en el precio fortaleciendo así la competencia ante el resto de empresas.

- Comodidad. Es cierto que por el momento, el porcentaje de compradores en la Red, es mucho menor que el que compra en tiendas off-line pero con el tiempo este porcentaje va aumentando. Las personas que empiezan comprando algún artículo por Internet enseguida comprueban que es mucho más cómodo, entre otras cosas porque no existen desplazamientos y económico, con lo que repiten con facilidad.

- Llegamos a un público más segmentado. Una vez que un cliente ha realizado una compra o se ha interesado por la empresa, la información que se posee de él es mucho más clara y concisa. Por eso ante una nueva 
información la empresa sabe con certeza a que clientes debe dirigirse, reduciendo costes innecesarios.

- Constante actualización. Las páginas web de empresas permiten dar una información actualizada en todo momento, lo que permite a la organización adaptarse a la situación y variar estrategias según las circunstancias.

- Al alcance de todos. En Internet no existen barreras en cuanto a distancia. La red permite a las empresas estar al alcance de todos en todo momento.

- $\quad$ Contagio por otros clientes. La Web 2.0 facilita la interacción con otros usuarios. Actualmente los comentarios de opinión en distintos blogs, o páginas web sobre productos y servicios están a la orden del día. Los clientes prefieren recibir consejo de gente ya han probado el producto y que tras su satisfacción recomiendan el producto o servicio. Además en estas conversaciones de intercambios de opiniones se piden consejo unos a otros y mejoran (en otros casos empeoran) la imagen de la empresa.

Para los clientes el principal beneficio de comprar a través de Internet, es además de encontrar productos más baratos, la información que se proporciona. A través de programas de búsqueda como puede ser Google o Yahoo el cliente encuentra con una sola palabra distintos productos, en los que puede comparar precios, características diferenciales, opinión de otros usuarios, etc. Lo que es una ventaja para los consumidores es un inconveniente para las empresas off-line que ven como la competencia se incrementa, además de encontrarse clientes cada vez más exigentes y mejor informados, difíciles de engañar.

\section{Turismo 2.0}

Navegando en la red encontramos que la unión de turismo y Web 2.0 es conocida como "Travel 2.0" o lo que es lo mismo "Viajar 2.0", "Turismo 2.0" o ETurismo. 
Según el estudio de España Conecta ${ }^{3}$ elaborado por Boston Consulting Group (multinacional de consultoría de gestión, líder en estrategia de negocios) existe una transformación clara de los sectores debido a Internet y su constante evolución, entre los que se encuentra el turismo. En dicho informe se apunta que el gran progreso del sector se debe principalmente a dos características: intensidad de uso de información para la planificación del viaje y comercialización de un servicio y no de bienes físicos. También se apunta la rapidez con la que el sector se adapta al canal online y pone como ejemplos las principales cadenas hoteleras como: Sol Meliá y NH que realizan más de un $40 \%$ de sus ventas a través de internet o las aerolíneas, donde destaca Vueling que canaliza un $70 \%$ gracias a la Red. En este aspecto y para comprender el Turismo 2.0 tenemos que añadir a este uso acelerado de Internet la aparición de elementos de socialización e interacción entre clientes y empresarios. Las criticas, opiniones y la posibilidad de contacto entre distintos usuarios unido al desarrollo de Internet crean el Turismo 2.0.

\section{Estructura del Turismo 2.0}

Ante el "universo" de Internet y la escasa investigación sobre el turismo a través de la Red resulta complicado establecer un orden para lo que los "gurús" llaman Turismo 2.0 o E-turismo. Para nosotros y por el momento, la estructura del Turismo 2.0 se puede dividir en base a dos soportes fundamentales: EI PC u Ordenador Personal y los Dispositivos Móviles. Incluir en esta clasificación el Ordenador Personal es algo evidente puesto que es el principal medio que los usuarios de internet utilizan para conectarse; no obstante en el último año hemos visto como los móviles se desarrollan de forma acelerada en el ámbito de Internet disponiéndose, tal y como auguran los expertos, a convertirse en la principal ventana a la Red.

Según el estudio elaborado por la compañía Neoyorquina Nielsen ${ }^{4}$ (líder global en medición e información de tendencias de mercado) se establece que la gran

\footnotetext{
${ }^{3}$ http://www.thebostonconsultinggroup.es/documents/file78287.pdf

${ }^{4}$ http://www.nielsen-online.com/intl.jsp?country=es
} 
sorpresa del año ha sido el despegue definitivo de Internet desde el móvil, de la mano de los Smarthphones con Nokia a la cabeza y su plataforma de conexión Symbian, seguida de iOs de Apple, Android de Google y el sistema operativo de Blackberry, en este orden. Además en dicho informe se apunta que la sociedad española cuenta con más de 38.4 millones de estos dispositivos móviles y más de nueve se conectan a la Red.

\section{Ordenador Personal}

En este apartado apuntamos información sobre el Turismo 2.0 que podemos localizar a través de un PC.

\section{Paginas donde el usuario busca información a través de opiniones}

A nuestro modo de ver, este tipo de páginas son las más representativas del llamado Turismo 2.0 puesto que unen perfectamente sus dos conceptos clave: turismo e interactividad entre usuarios. Estas actúan como si de una agencia de viajes convencional se tratase pero con la ventaja de que no existen comisiones y que no hay un único agente de viajes si no que todos los usuarios de la página actúan como agentes, con lo cual las recomendaciones o criticas de un lugar o servicio se multiplican. Pero no todo son ventajas, en esa marea de opiniones ¿Cuáles son verdaderas? ¿Qué filtro se sigue para canalizar críticas y opiniones? ¿Deberíamos de creer todo lo que se aconseja o se critica?

En este apartado y ante la ausencia de cualquier ranking o clasificación oficinal sobre Turismo 2.0, nos hemos limitado a estudiar únicamente tres páginas: Tripadvisor, Minube y Holiday-Truth. La primera de ellas se ha elegido principalmente por su gran actividad, número de visitas, número de usuarios, etc. en definitiva por su importancia mundial dentro de las páginas donde el usuario busca información a través de opiniones. Minube, además de ser elegida por su nacionalidad española también se elige por otra serie de aspectos como: reciente creación, elevado número de usuarios e interés 
general de la página. La última elección, Holiday-Truth se estudia especialmente por estar menos desarrollada y presentar a simple vista mayor número de carencias que podrían ser comparadas con los dos sitios Webs anteriormente mencionados. Pero sin lugar a dudas en este apartado se podrían haber analizado otras muchas páginas del tipo: Euroresidentes, Viajeros.com, Viajeros anónimos, La vuelta al mundo.net, Dime Dónde Ir, Los viajeros, etc. que podemos encontrar en Google simplemente introduciendo la frase: "Consejo para viajar". Cada día surgen páginas nuevas que se podrían apuntar en esta clasificación pero no seríamos capaces de controlarlas, encontrarlas y analizarlas en conjunto.

Una vez explicada la metodología del estudio procedemos a presentar el análisis para este primer bloque de páginas dedicadas al Turismo 2.0.

En primer lugar podemos decir que de los sitios Web analizados, Minube es la página que tiene mayores cualidades para presentar un destino. El sitio Web presenta la información de forma clara y comprensible. Los contenidos son útiles, actualizados y acordes con el propósito de una página de Turismo 2.0. En el caso de Tripadvisor cabe decir que es una página de mayor trascendencia que Minube pero, en relación a la exposición de la información acerca de los destinos turísticos, esta última tiene para nosotros mayor trascendencia. A nivel de contenido Tripadvisor posee mayor variedad de opciones que permiten al usuario organizar su viaje con un abanico amplio de oportunidades. Finalmente en relación la última página analizada de este bloque, Holiday-Truth, nos sorprende la falta de organización y estructura de la Web lo que dificulta su comprensión y navegación; así como la ausencia de información importante del tipo: enlace contacte con nosotros, a cerca de nosotros, etc. con la que se conseguiría una mayor confianza en el usuario.

De forma general, para las tres páginas, resaltamos la facilidad con la que el usuario puede formular una crítica ya sea de un servicio o de un destino turístico. Simplemente con registrarse en la página se tiene potestad para dejar el comentario que se crea oportuno sin pasar previamente ningún filtro que autorice la publicación o que confirme que realmente es cliente de un servicio o 
ha visitado un destino turístico. Desde un punto de vista personal consideramos que esto puede acarrear tanto criticas como recomendaciones o consejos falsos, y derivar así en el deterioro de la imagen de un servicio o destino, reducción en el número de clientes o visitantes, pérdidas económicas, influencia en la credibilidad para el público objetivo, etc.

La importancia que en la actualidad tienen este tipo de páginas se ve reflejada con su número de usuarios: Tripadvisor: 20.000.000, Minube: 132.839 HolidayTruth: 55.651. Estas cifras deberían ser suficientes para establecer un organismo capaz de controlar el movimiento de comentarios, criticas, recomendaciones o consejos.

Sea de una forma u otra, positiva o negativa, lo cierto es que estos sitios Web influyen en la promoción del turismo. Sin ir más lejos, Tripadvisor a través del número de críticas de sus usuarios establece un ranking, tanto mundial como por países, de los 25 mejores destinos; ranking que es analizado con detenimiento por aquellos que buscan un lugar para realizar sus vacaciones. Cada vez son más los que buscan consejos en otros usuarios o simplemente contemplan los comentarios de cada servicio o destino, personalmente nos incluimos entre estos buscadores de opiniones.

Del Libro Blanco ${ }^{5}$ de Minube, elaborado por los creadores de la página así como de distintos profesionales que comparten sus ideas sobre cómo sentar las bases de lo que ellos llaman Nuevo Turismo, extraemos la siguiente frase para finalizar este primer análisis: "El nuevo viajero ha surgido de esta revolución tecnológica y de un cambio generacional que ha llevado nuevos valores y hábitos de consumo. Para el sector es como si cambiáramos su sistema métrico decimal".

\section{Páginas donde el usuario busca información a través de ofertas}

En esta segunda clasificación, a diferencia de la primera, el motivo principal de los usuarios es conseguir la mejor oferta para visitar un destino turístico, ya sea

\footnotetext{
${ }^{5}$ www.minube.com
} 
en cuanto a hoteles, vuelos, restaurantes, etc. Por regla general muchas de las páginas que hemos mencionado en el primer apartado se surten de estas segundas para elaborar la mejor opción y presentársela al usuario, además de encontrarse con las críticas y opiniones de la página. Por poner un ejemplo podemos decir que Minube selecciona de Booking los hoteles, vuelos y paradores más económicos, eso junto con los comentarios de sus usuarios permiten que la selección sea mucho más consensuada.

En este caso hemos decidido analizar los siguientes sitios Web: Booking y Trivago. Estas son consideradas unas de las más activas a nivel mundial, dentro de las páginas dónde el usuario busca información a través de ofertas. Cabe destacar que este caso las ofertas están únicamente relacionadas con alojamientos. Además podemos mencionar que en este apartado se podrían haber analizado otras muchas páginas como es el ejemplo de Kayak que últimamente está aumentando su publicidad en distintos medios como la televisión.

Según el análisis de las páginas podemos aportar que funcionan buscando los precios más económicos de cada servicio entre distintos sitios web. En la actualidad son firmes competidores de las agencias de viajes tradicionales que tienen que saber adaptar sus precios a este tipo de páginas.

Además es necesario resaltar la importancia de los servicios turísticos que en estos casos son los que forman la imagen de una ciudad, a través de fotografías, opiniones, rankings, etc. En este caso el destino queda relegado a un segundo lugar siendo el principal motor de búsqueda el alojamiento. Aún así la importancia de los destinos turísticos no disminuye puesto que es imprescindible para buscar el hotel. Los datos que se proporcionan de las ciudades y lugares son secundarios, es decir, se pueden entrever en los comentarios de usuarios, importancia de los hoteles, imágenes, etc. En este sentido la ciudad y su imagen se proyectan a través de los establecimientos hoteleros. 
Otro dato que nos llama especialmente la atención es la inclusión en todas las páginas analizadas hasta el momento, de enlaces a distintas redes sociales, principalmente Facebook y Twitter. Este apunte nos remarca la importancia que cobran las redes sociales en un sector como el turismo.

Finalmente y para dejar constancia de la importancia de ambas páginas destacamos su número de visitas: Trivago supera los diez millones de visitas únicas al mes y Booking recibe treinta millones de visitas únicas al mes. Si comparásemos estas cifras con las visitas a una agencia de viajes tradicional quedaría al descubierto la importancia que cobra, en la actualidad, este tipo de páginas.

\section{Páginas de Mapas y Direcciones}

En esta clasificación incluimos aquellas páginas que a través de mapas presentan al público distintos destinos turísticos. En este caso podemos destacar dos programas que, en lo referente a esta temática, resaltan por encima de los demás: el servidor Google Maps y la aplicación Google Earth. Ambos permiten visualizar rutas elaboradas por otras personas (en los que se incluyen fotografías, consejos de restaurantes y hoteles e incluso opiniones). Además de buscar los lugares que a uno le interesan y poder visualizarlos en distintos estilos de mapas, acercando la imagen hasta unos centímetros del suelo. El formato tanto de Google Maps como Google Earth es de fácil comprensión, su utilización es sencilla y muy eficaz. Con estos ejemplos divulgamos aún más la importancia que tiene en la actualidad el buscador Google como la página más visitada de Internet.

Las páginas de Mapas y Direcciones aportan gran información de destinos turísticos a través de la Red. Los usurarios de Internet buscan la localización de los lugares que pretenden visitar, a través de este tipo de mapas; así como fotografías o comentarios de mapas realizados por otros usuarios. 
La nueva versión de Google Earth 6 además de buscar un lugar permite grabar un viaje o importar datos GPS. Asimismo cuando un usuario realiza un mapa de sus viajes puede compartirlos con otros usuarios.

Igualmente, en este apartado podríamos incluir otras páginas de elaboración de rutas como pueden ser viamichelin.es o guiarepsol.com.

\section{Páginas de Audio y Vídeo}

Estas páginas a través de Podcast, archivos multimedia, normalmente de audio y vídeo que un usuario puede descargar y visualizarlo cuando quiera, albergan distintos temas entre los que se encuentra el turismo.

Este tipo de formato es muy utilizado en distintas páginas con contenido turístico puesto que permiten visualizar los destinos y posteriormente establecer un comentario. Cabe resaltar la importancia tanto de las imágenes como de los videos para el sector turístico que ayudan a formar una idea previa del viaje y del servicio en general. Para este apartado hemos seleccionado la página Travelago ${ }^{6}$ y Youtube $^{7}$, la primera de ellas se ha elegido por ser una de las videotecas multimedia de viajes más grandes del mundo, en la que se puede acceder a destinos, hoteles, atracciones, museos, cruceros etc. En lo referente a Youtube se ha seleccionado por tratarse de la mayor comunidad

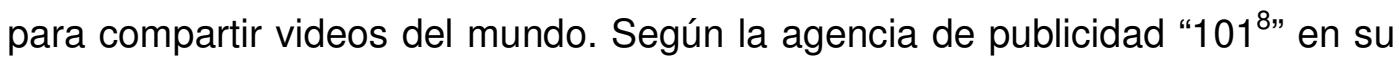
video actualizado sobre el uso de las redes sociales en España se aportan las siguientes cifras que destacan la categoría de la página: Youtube es una de las cuatro palabras más buscadas en Google y cada minuto se suben 20 horas de video a Youtube.

Travelago se funda en 1999 en Estados Unidos y es una guía de viajes de vídeo de los destinos turísticos más importantes del mundo. Incluye Streaming de vídeo con lo que ofrece una visita virtual de un destino, hoteles y atracciones. Se ofrece así, una visita al futuro turista antes de llegar al destino.

\footnotetext{
6 www.travelago.com

7 ww.youtube.com

${ }^{8}$ www.101.es
} 
Además del video se aportan explicación escrita del lugar. Nos llama especialmente la atención que se especializa en cruceros, un tipo de viaje que hasta el momento no se destacaba en ninguna de las páginas analizadas y que en general los turistas asocian su promoción con una agencia de viajes convencional. En cuanto a su formato y estructura podemos aportar que se trata de una página de fácil comprensión donde su navegación es fácil y rápida. El sitio Web se presenta bajo un fondo blanco y con las letras e iconos de colores azul y verde oscuro que propician la visión en conjunto.

En el caso de Youtube esta es una página que nace en Estados Unidos en 2005 y que en la actualidad permite a miles de millones de usuarios que encuentren, vean y compartan vídeos creados de forma original.

La principal diferencia que a simple vista encontramos entre Travelago y Youtube es en el formato. Youtube presenta una estructura más afianzada, de mejor calidad e incluso más ordenada. En el caso de Youtube basta una frase o un nombre para encontrar el video adecuado, en el caso de Travelago necesitamos buscar nuestro destino a través de un mapamundi. Otra diferencia evidente es que Youtube no se centra en videos de carácter únicamente turísticos si non que es su página podemos encontrar videos de todo tipo. Son de gran importancia para el sector aquellos que destacan aspectos relevantes de distintas ciudades en forma de promoción turística. Además en Youtube cualquiera puede subir un video a la página una vez que nos hacemos usuarios de la misma, mientras que en Travelago son sus propios creadores quienes surten al sitio Web de videos.

Podemos finalizar este apartado aludiendo a la importancia que para el sector turístico tienen las imágenes y videos. Existe una diferencia importante en relación a la promoción turística convencional, puesto que a través de guías escritas, revistas o catálogos el cliente no tenía una imagen completa del destino a visitar esencialmente por la complejidad del servicio turístico dónde sólo se alcanzaba una comprensión clara in situ, y que gracias a estos medios se permite una visión muy aproximada del lugar a visitar. 


\section{Blogs}

Los blogs como todos sabemos son sitios Web en los que su autor publica periódicamente (en otros casos simplemente una vez) artículos del tema que él elige. Del blog "Blogmundi " "extraemos las siguientes apreciaciones sobre por qué tener un blog:

Gracias a él tenemos presencia en la Web y nos damos a conocer entre profesionales del mismo sector, se establece en el blog comentarios de distintos lectores, creando interacción e interés, el propio "bloguero" puede actualizar el sitio Web sin esperar a que un diseñador lo modifique, gracias al cual podemos realizar cambios diariamente. Con los blogs conseguimos notoriedad en los buscadores que seleccionan las palabras clave. Podemos probar nuevas ideas y obtener respuestas de inmediato, así como introducir publicidad de nuestros productos.

Existen blogs de los temas más variados, entre ellos, de turismo, en concreto buscando en Google "Blogs de turismo" aparecen 20.700.000 resultados, del que hemos elegido Blogturistico.com, pero podríamos seleccionar otros muchos como: Vagamundos, Nautilia viajando raro, La langosta viajera, Diario del viajero, Blog de viajes, Gridskipper, Hotel chatter, Bajocoste, Megustaelturismo.es, etc.

En el caso de Blogturistico.com sorprende la gran cantidad de información que proporciona al lector en el ámbito del turismo.

El blog se forma en base a un fondo blanco y las letras e imágenes se presentan en colores morados. La clasificación de la información se divide en varios apartados: para favoritos, lo más destacado, secciones (balnearios, castillos, catedrales, espectáculos y guías online), promociones destacadas y artículos. En cuanto a los artículos se refiere podemos destacar la gran cantidad de publicaciones de contenido turístico. La mayoría describen lugares

\footnotetext{
${ }^{9}$ www.blogmundi.com 
y monumentos y al final del mismo los usuarios dan su opinión o expresan sus vivencias.

Para finalizar este apartado podemos comentar que los blogs también incluyen publicidad en sus páginas, en este caso en el margen superior se incluye publicidad por parte de la empresa E-dreams, entre otras.

\section{Redes sociales}

Tal y como explican en su obra "Conectados", Christakis, N y Flowler.J las redes sociales se pueden dividir en Redes Sociales Virtuales y Redes Sociales Reales.

Las Redes Sociales Virtuales y las Reales, conservan las mismas características, aunque bien es cierto que las relaciones son distintas. La interacción entre personas en las Redes Sociales Virtuales es mucho más abierta (en muchas ocasiones se agrega a gente con la que no se contactaría en una relación social real), entre otras muchas posibilidades permiten mantener y recuperar relaciones sociales reales y facilitan la conexión entre las redes. La diferencia principal entre ambas Redes es, como su propia palabra indica, que unas necesitan de las nuevas tecnologías para llevarse a cabo y las otras no.

Hoy en día hablar de "Social Media" es algo habitual y son muchos los que poseen un perfil en una Red Social Virtual. Estas se propagan de forma acelerada y las hay de todo tipo: internacionales, españolas, sólo para enviar mensajes, para compartir fotografías, información de carácter profesional, etc.; y para todos los públicos (más jóvenes y más mayores). Tanto es así, que las redes sociales virtuales están comiendo terreno a los medios de comunicación tradicionales.

En nuestro país la principal Red Social, por el momento, es Facebook, según el estudio realizado por $\mathrm{AIMC}^{10}$ sobre internet entre el 20 de octubre y el 13 de

\footnotetext{
${ }^{10}$ www.aimc.com
} 
diciembre de 2009. A continuación apuntamos las características más destacables de esta Red Social y comentaremos la inclusión del turismo dentro de la misma.

El propio Facebook" se define como "un servicio social que conecta a la gente con amigos y otros que trabajan estudian y viven cerca".

En la actualidad, todo aquel que quiera conectarse a Facebook sólo tiene que crear un perfil con sus datos (nombre, edad, lugares de trabajo, universidades, etc.), a través de un e-mail y en la página de Facebook. Una vez dentro, se buscan los distintos conocidos o amigos por el nombre, o se intentan acceder a nuevos contactos buscando dentro de los amigos de nuestros amigos. Con tus amigos agregados puedes enviar mensajes, compartir videos, establecer un estado para cada día, jugar a los juegos que la propia red ofrece, bajar aplicaciones, ver páginas de distintos temas, etc.

Facebook se convierte en la Red Social más utilizada en todo el mundo, desbancando así a su principal competidora y hasta hace poco líder en el mundo de las Redes Sociales, MySpace.

En esta Red Social, al igual que en otras muchas, el sector del turismo encuentra otra forma de promocionar sus productos. Se crean así páginas dentro de Facebook sobre distintos subsectores del turismo: agencias de viajes, agencias de alquiler de coches, cadenas hoteleras, compañías aéreas, casas de turismo rural, Ayuntamientos que promocionan su ciudad, etc. Gracias a estas páginas se presentan al resto de internautas características de sus productos, fotografías, promociones puntuales, así como interacción con el usuario. Se pretende una socialización de la página donde se establezca el contacto entre los visitantes y creadores de forma rápida y real.

Subrayamos la importancia de los nombres de la páginas para facilitar la búsqueda al usuario, ya que en Facebook buscamos principalmente con una o dos palabras, es decir, para buscar información sobre el turismo de A Coruña

11 www.facebook.com 
sería imprescindible que ante la palabra Coruña en el buscador de Facebook apareciesen las páginas dedicadas al turismo de la ciudad.

Se podrían destacar aquí páginas de Facebook que funcionan de forma rentable y aportando multitud de información al usuario, como pueden ser: Página oficial de turismo Madrid (Turismo Madrid), Hotel Quintana del Caleyo, Top Rural, Casa Rural la Charruca, etc.

Como vemos el turismo, al igual que otros sectores, ven en Facebook y en otras Redes Sociales, una posibilidad más de promoción y contacto con sus usuarios. Los datos son halagüeños para la comercialización y publicidad a través de este tipo de medios.

\section{DISPOSITIVOS MÓVILES}

Para comenzar este apartado es necesario explicar que gracias a internet en el móvil podemos acceder a las páginas que se han analizado en el apartado anterior, pero existen algún tipo de aplicaciones a las que únicamente podemos acceder a través de dispositivos móviles. Estas últimas serán las protagonistas de este segundo apartado.

Para hacernos una idea de la importancia que los Smartphones tienen en la actualidad podemos apuntar algunos datos del estudio realizado por Accenture con la colaboración de la $\mathrm{MMA}^{12}$ (Mobile Marketing Association) en la que han participado 31 compañías del sector.

- $\quad$ En España la actividad para el conjunto de actividades de Marketing durante 210 presenta un crecimiento del 17,8\% sobre 2009 con una actividad que supera los 38 millones de euros.

- La inversión dedicada a la compra de medios supone el 50\% de dicha actividad, alcanzando los 19 millones de euros.

\footnotetext{
${ }^{12}$ www.mmaglobal.com/main
} 
- Las previsiones del sector hacia 2012 son optimistas, con un crecimiento medio del 53\%, con expectativas similares a las del estudio de 2009.

- Internet Móvil sigue siendo la actividad más importante en volumen, aunque ostras tipologías, como las Aplicaciones y Advergamings han ganado relevancia gracias al desarrollo de nuevos terminales.

- Telecomunicaciones, Automoción y Viajes son los sectores más activos durante este año.

- Las Redes Sociales, el geomarketing y las aplicaciones, aparecen como las palancas clave de desarrollo del marketing móvil para 2011.

A todo ellos podemos sumar la importancia de la portabilidad del móvil y de ser un aparato de uso personal que siempre intentamos llevar con nosotros. Precisamente esta una de las cualidades más destacadas por los creadores de publicidad, expertos en Marketing, desarrolladores de aplicaciones móviles, etc. ya que ven en los dispositivos móviles una ventana para el progreso de sus productos.

Además cabe destacar la inclusión de GPS en los Smartphones que facilitan la creación de distintas aplicaciones y ofrecen una gama más amplia de posibilidades para el negocio. Tanto es así que la empresa Domino's Pizza ${ }^{13}$ es su aplicación para Smartphones permite comprar la pizza deseada por el cliente sin necesidad de señalar su ubicación.

Además de la información que acabamos de apuntar creemos necesario aclarar, en este momento, los siguientes términos que serán clave para entender el desarrollo del apartado:

Geolocalización: La geolocalización o georreferenciación consiste en situar un elemento en el espacio, elaborando un sistema de coordenadas.

\footnotetext{
${ }^{13}$ www.youtube.com/watch?v=1ahPy0mrodM
} 
Realidad aumentada: La realidad aumentada trata de proporcionar información a través de la unión dos elementos, el mundo real y elementos virtuales.

Apps o aplicaciones: programas informáticos que podemos utilizar en nuestro móvil.

En este bloque de "Dispositivos Móviles" analizaremos varios ejemplos de aquellas aplicaciones que tienen o pueden tener importancia en el sector turístico. Se han elegido tres por ser noticia últimamente y por su reciente creación pero se podrían haber analizado otras muchas como, Layar, Fourdsquare, Wikitude, Yelp, etc.

\section{Bluguía}

Bluguía $^{14}$ se puede entender como una audio-guía para toda una ciudad. El modelo se basa en una guía turística portable, un dispositivo multimedia con geoposicionamiento vía satélite que conduce al usuario por rutas predeterminadas (turística, gastronómica, cultural...) y aporta información sobre cada punto de interés. Bluguía se puede utilizar como una audio-guía tradicional o como una aplicación para a un Smartphone. El funcionamiento del dispositivo es sencillo pero muy atractivo y potente. El usuario simplemente debe seleccionar su idioma, escoger la ruta predeterminada y descubrir así los puntos más interesantes de la ciudad. Su repercusión a nivel turístico es inmejorable, permite difundir la imagen de la ciudad de una forma cómoda y rápida.

Son varias las ciudades españolas que cuentan con este servicio como Vigo, Murcia, Palma de Mallorca, etc. y su Director Pablo Conde nos comentaba en las Jornadas B-Web II celebradas en la ciudad de A Coruña que en poco espacio de tiempo estarían presentes en otras ciudades a nivel internacional. Uno de los servicios que más nos llama la atención es Bluguía para el Camino Francés, con el que gracias al sistema GPS existe menor posibilidad de pérdida en el camino y además los peregrinos pueden disfrutar de

\footnotetext{
${ }^{14}$ www.bluguia.com
} 
explicaciones culturales de los distintos monumentos así como recibir información sobre el establecimiento de restauración u hotel que mejor se adapta a sus necesidades.

Además gracias a Bluguía encontramos cambios en la promoción del turismo, la ciudad se promociona a través de la voz e imágenes de un guía que comentan in situ el paso por la ciudad creando una mayor comprensión en el visitante. Asimismo, se dan a conocer los mejores restaurantes y hoteles del lugar elaborando una publicidad inmejorable de los servicios turísticos.

Consideramos por tanto que, Bluguía es un proyecto excepcional que compatibiliza perfectamente las nuevas tecnologías con el turismo y sin duda le ofrece al sector una oportunidad para modernizarse, así como una nueva forma de promoción turística.

\section{Aplicación Cerca de Mi, Realidad aumentada de Páginas Amarillas}

La nueva aplicación para Smartphone de Páginas Amarillas ${ }^{15}$, Cerca de Mi, permite a los usuarios encontrar todo lo que necesiten cerca de donde estén. Esto incluye hoteles, restaurantes, teatros, cines, etc. y demás servicios que tienen influencia en el sector turístico. La forma de uso es la siguiente: a través de la cámara del móvil (en un primer momento sólo estaba disponible para ¡Phone pero en la actualidad se puede utilizar con teléfonos Android) el usuario visualiza el lugar donde se encuentra, debe entonces seleccionar el servicio sobre el que necesita información (hoteles, restaurantes, peluquerías, etc.), a continuación en la misma imagen real que se ve a través de la cámara irán apareciendo iconos virtuales que señalan los servicios más cercanos así como información sobre los mismos. En estos iconos se muestra la siguiente información: su dirección, teléfono, correo electrónico y dirección web; la aplicación permite llamar directamente al establecimiento seleccionado, añadir el contacto a la agenda, guardarlo en favoritos o enviarlo con comentarios a otros usuarios.

\footnotetext{
${ }^{15}$ www.paginasamarillas.es
} 
Como servicios adicionales se destaca: cines y teatros más cercanos, posibilidad de consultar la cartelera de cine, pronóstico del tiempo, la nieve de las estaciones de esquí o las cámaras de tráfico.

Como vemos esta aplicación es una forma cómoda, rápida y que está disponible en todo momento gracias a la portabilidad del teléfono móvil y que este nos acompaña siempre. La empresa Páginas Amarillas ha sabido adaptarse a los tiempos y mejorar su clásico directorio de teléfonos que en los últimos años era sustituido por la búsqueda de información a través de páginas web.

Para las empresas turísticas aparecer en este tipo de aplicación es fundamental puesto que las personas que más lo utilizan son aquellas que se encuentran en un lugar desconocido y que buscan información fiable y en el momento.

\section{Facebook Places}

Facebook Places es una aplicación oficial de Facebook para móviles iPhone, Android y Blackberry. Desde Facebook se define como una aplicación donde sus usuarios pueden: compartir el lugar dónde uno se encuentra, conectar con los amigos que están cerca y conseguir ofertas en distintos productos.

La forma de utilizar Facebook Place es la siguiente: en su menú aparece el icono de "lugares" donde se marcan distintos comercios, lugares públicos, parques y en definitiva cualquier lugar que está cerca. La cuestión es hacer Check-in (también se puede hacer en otras aplicaciones como Foursquare) en alguno de estos lugares, automáticamente esta información pasa a formar parte de nuestro muro en Facebook donde todos nuestros amigos pueden saber nuestra localización. Pero la aplicación va más allá, son muchas las tiendas y comercios que realizan descuentos (en otros casos donaciones a ONGs) por chequear dentro de su establecimientos, como por ejemplo: E Corte Inglés, Starbucks, BBVA, H\&M, etc. pero sin duda el que más nos interesa para este artículo es la cadena hotelera Sol Meliá que realiza un 50\% 
de descuento en los restaurantes de la cadena, en los buffet de desayuno y spa.

Sin duda Facebook, al igual que otras compañías están revolucionando el mundo del móvil y de comercialización y promoción. Como acabamos de ver, en cualquiera de los tres ejemplos, el sector turístico tiene infinidad de oportunidades gracias a este tipo de aplicaciones.

\section{CONCLUSIONES}

Para poner fin a este artículo hacemos mención a la siguiente frase extraída del Libro Blanco de Minube ${ }^{16}$ : "El siguiente paso es que la industria turística piense en global. Lazarse al mercado debe implicar la búsqueda de clientes en cualquier punto geográfico de este mundo".

Con esta aportación remarcamos la importancia de la socialización y expansión que necesita el sector turístico para seguir adaptándose a la evolución que presenta el cliente actual. No obstante como hemos comprobado a lo largo del artículo, con ejemplos reales, es sector está despertando y evolucionando para ajustarse a las necesidades que solicitan sus clientes.

En forma de conclusiones destacamos los siguientes puntos:

\footnotetext{
${ }^{16}$ www.minube.com
} 
Importancia de las críticas y comentarios. Son, como mencionábamos en el estudio de Tripadvisor, un elemento clave del Turismo 2.0, que cada vez cobran mayor importancia para decidir ante uno producto $u$ otro. De igual forma consideramos que estas críticas y comentarios están poco controladas y prácticamente no pasan ningún filtro antes de su publicación, lo que puede, en un futuro, acarrear problemas de imagen para una empresa o destino.

Valor de las imágenes y videos para construir, en la mente del consumidor, una idea clara de un servicio turístico, que anteriormente se dificultaba a través de guías escritas, revistas o catálogos.

Desarrollo de la promoción turística gracias a la utilización de las Nuevas Tecnologías. En este punto consideramos que las aplicaciones para Dispositivos Móviles están en el punto de mira y pueden aportar multitud de posibilidades de comercialización y promoción para el sector. Es importante destacar aquí la cita que apuntábamos en el apartado anterior sobre el estudio elaborado por la MMA (Mobile Marketing Association) donde se decía que los sectores de Telecomunicaciones, Automoción y los Viajes están siendo los más activos, en lo que a aplicaciones móviles se refiere, de este año. Esta aportación es de gran importancia para destacar el esfuerzo realizado por el sector turístico en el desarrollo de Nuevas Tecnologías.

Con ejemplos como Tripadvisor, Booking, Youtube, Facebook Places, Bluguía, y Páginas Amarillas, entre otros, vemos de forma real el desarrollo y cambio de la promoción a nivel turístico apostando por una mayor socialización e interactividad con el usuario.

Finalizamos este artículo tal y como lo empezamos, mencionando al Adprosumer, ese nuevo tipo de cliente en el que deben pensar las empresas, en nuestro caso las turísticas, a través del Turismo 2.0. 


\section{BIBLIOGRAFÍA}

Christakis, A. N. Fowler, H.J.(2010) Conectados. Taurus, 2010. Madrid.

Vogeler, C (2000). El mercado turístico. Estructura, operaciones y procesos de producción

http://www.thebostonconsultinggroup.es/documents/file78287.pdf

http://www.nielsen-online.com/intl.jsp?country=es

www.minube.com

www.youtube.com

www.travelago.com

www.101.es

www.blogmundi.com

www.aimc.com

www.facebook.com

www.mmaglobal.com/main

www.youtube.com/watch?v=1ahPy0mrodM

www.paginasamarillas.es/

www.bluguia.com

Para citar este artículo:

Sánchez Amboage, Eva (29-07-2011). EL TURISMO 2.0. UN NUEVO MODELO DE PROMOCIÓN TURÍSTICA.

REDMARKA - CIECID - Unidad de Investigación en Marketing Aplicado-Universidad de A Coruña

Año III, Número 6, V1, pp.33-57

ISSN 1852-2300

URL del Documento: cienciared.com.ar/ra/doc.php? $\mathrm{n}=1490$

URL de la Revista: $\underline{\text { cienciared.com.ar/ra/revista.php?wid=39 }}$ 